\title{
1 Microbial Food Safety in the Maryland Direct-to-Consumer Poultry Supply Chain
}

2 Patrick A. Baron ${ }^{1 *}$, David C. Love ${ }^{2,6}$, Shanna Ludwig ${ }^{2}$, Kathryn Dalton ${ }^{2}$, Jesper Larsen ${ }^{5}$, Gabriel

3 K. Innes ${ }^{2}$, Meghan F. Davis ${ }^{2 . \S}$, Christopher D. Heaney ${ }^{2,3,4 . \S}$

4 Author Affiliations:

$5 \quad{ }^{1}$ Department of Health and Human Values, Davidson College, Davidson, North Carolina

$6{ }^{2}$ Department of Environmental Health and Engineering, Johns Hopkins Bloomberg School of Public Health,

7 Baltimore, Maryland

$8 \quad{ }^{3}$ Department of Epidemiology, Johns Hopkins Bloomberg School of Public Health, Baltimore, Maryland

$9{ }^{4}$ Department of International Health, Johns Hopkins Bloomberg School of Public Health, Baltimore, Maryland

$10{ }^{5}$ Department of Bacteria, Parasites and Fungi, Statens Serum Institut, Copenhagen, Denmark

$12{ }^{6}$ Center for a Livable Future, Johns Hopkins Bloomberg School of Public Health, Baltimore, Maryland

$13{ }^{\S}$ Equally-contributing co-authorships

$14 *$ Corresponding author

Abstract: Direct-to-consumer food marketing is a growing niche in the United States food

17 supply chain. Food animal producers who use direct marketing may employ different production

18 models and standard practices from producers selling animal products to the conventional food

19 system. Direct-to-consumer food supply chains (generally and specifically regarding food animal

20 products) are relatively unexplored in food safety and health research. We conducted a cross-

21 sectional, market-basket analysis of the Maryland direct-to-consumer poultry supply chain to

22 assess food safety. We analyzed 40 direct-to-consumer commercial poultry meat products (one

23 product per farm) for Escherichia coli, Staphylococcus aureus and Salmonella spp. using

24 culture-based methods. Isolates underwent antimicrobial susceptibility testing. E. coli and $S$.

25 aureus were recovered from $9 / 40(23 \%)$ and 12/40 (30\%) of poultry meat samples, respectively.

26 Of interest for comparing direct-market and mainstream supply chains for food safety risks, no

27 Salmonella isolates were recovered from any direct-market sampled poultry products and no

28 multidrug resistance was observed in E. coli and S. aureus isolates. Microbial outcomes were 
29 compared to a survey of poultry production and processing practices within the same study

30 population.

\section{Importance:}

32 This study demonstrates substantially lower rates of antimicrobial-resistant (AMR) microbial

33 pathogens in the market-basket products from Maryland direct-market broiler poultry supply

34 chain compared to rates of AMR in the conventional supply chain for similar retail meat

35 products from NARMS. We further describe the landscape of the statewide supply chain for

36 direct-market poultry, focusing on characteristics related to risk management strategies applied

37 to microbial food safety. These findings are of public health significance for both the research

38 and policy communities; these data provide an initial evidence base for more targeted research

39 evaluating potential risk factors for microbial food safety in the direct-to-consumer supply chain.

40 These data will also assist the Maryland Department of Agriculture and other state-level agencies

41 with oversight of food safety issues to guide policy efforts for direct-market poultry production

42 and sales.

43 Keywords: food safety, microbiology, livestock, agriculture, sustainability, antimicrobial

44 resistance, antibiotics, epidemiology, supply chain, contamination, market-basket 


\section{Introduction}

52 Escherichia coli, Salmonella spp., and Staphylococcus aureus are major causes of bacterial

53 foodborne illness; however, US population exposure to these pathogens through non-industrial

54 supply chains for livestock products is virtually unexplored in health and food safety research.

55 The Centers for Disease Control and Prevention estimates that 1 in 6 people in the US acquire

56 foodborne infections every year, with 128,000 hospitalizations and $\sim 3,000$ annual deaths [1].

57 Incidence of O157 and non-O157 Shiga-toxin producing E. coli (STEC) are estimated to cause

58 illness at rates of 1.15 and 1.17 per 100,000, respectively [2]. Salmonellosis caused an estimated

$591,027,561$ cases of foodborne illness in 2013 in the US, resulting in $\sim 19,000$ hospitalizations and

60380 deaths [3]. Other bacterial pathogens commonly associated with foodborne illness include $S$.

61 aureus intoxication [3]. A review of food safety data from 1998-2008 indicates that poultry

62 products contaminated with pathogenic bacteria comprised $17.9 \%$ of the annual burden of

63 foodborne illness cases caused by bacterial exposure [4].

64 Industrial food animal production methods raise animals in high densities and producers often

65 routinely use antimicrobials for disease prevention and therapeutic purposes [5-9], which may

66 facilitate selection for antibiotic resistance among zoonotic bacteria. Antimicrobial resistance

67 among foodborne bacterial pathogens is a complicating factor in foodborne illness;

68 antimicrobial-resistant infections resulting from human exposure to foodborne bacteria caused an

69 estimated 430,000 illnesses in the US in $2012[10,11]$. The model(s) currently in use for direct-

70 market poultry production have not been adequately investigated for their potential to facilitate

71 selective pressure for antimicrobial resistance in foodborne pathogens. 
72 The prevalence of microbial foodborne pathogens in consumer poultry meat products coming

73 from the direct-market poultry supply chain remains relatively unexplored in health research.

74 Some recent research has focused on the epidemiology of Listeria in the production

75 environments of direct-to-consumer farms [12] and of Salmonella spp. in pastured-poultry

76 production [13]. Only a handful of studies have evaluated microbial food safety risks in direct-

77 market poultry supply chains $[14,15]$; only one study addressed these issues through a market-

78 basket and consumer exposure research lens [16]. This single study contained several

79 methodological limitations which limit the interpretation of these findings (see Supplement).

80 The current study addresses the research gaps surrounding microbial food safety of direct-

81 marketing systems for poultry in Maryland and builds on qualitative research in this population

82 which demonstrated that the models, practices and inputs used in Maryland direct-market poultry

83 production depart substantially from the typical models and practices of industrial-scale poultry

84 production [17]. We therefore hypothesized that these inter-supply chain differences contribute

85 to different microbial food safety outcomes for consumer poultry products in this supply chain

86 than those typically observed in the industrial food system, particularly with regard to the

87 prevalence of multi-drug resistant (MDR) foodborne pathogens. This study had four specific

88 aims: (1) describe the prevalence of E. coli, Salmonella spp., and S. aureus in a market-basket

89 sample of raw poultry meat purchased in the Maryland direct-market poultry supply chain; (2)

90 characterize the antimicrobial resistance phenotypes of any isolates detected by culture; (3)

91 compare these outcomes to relevant food safety data from National Antimicrobial Resistance

92 Monitoring System (NARMS) and other independent peer-reviewed research; and (4) use

93 matched data obtained with a survey tool from the same participating farms and poultry 
94 processors to explore associations between farm characteristics and observed food safety

95 outcomes.

2 Methods and Materials

97 Enrollment and Recruitment

98 We identified participants via publicly-available commercial registries that promote direct-market

99 agricultural producers in Maryland, particularly the databases maintained by University of Maryland

100 Agriculture Extension program [42]. As a secondary strategy, we used snowball sampling [18] to

101 identify participants whose contact information was not available through the aforementioned

102 sources. Participants were recruited via email or phone contact and offered a $\$ 20$ cash incentive. The

103 lead author conducted all of the surveys at the farms or homes of participants, and purchased a

104 sample of frozen poultry at the conclusion of each survey. The Johns Hopkins Bloomberg School of

105 Public Health Institutional Review Board approved this project and participants provided written

106 informed consent for survey and oral consent for meat sampling.

107 Survey tool

108 We administered a survey questionnaire to a broad sample of Maryland direct-market poultry

109 producers. The questions in the survey tool focused on descriptive characteristics and workplace

110 practices of small-scale poultry production and processing models. A copy of the survey is

111 included in the supplement. These factors included: scale and size of production and processing

112 operations; professional experience of producers and processors; antimicrobial usage in poultry

113 production; maintaining multiple animal species in close or overlapping proximity; sanitary

114 practices during slaughter and processing; poultry production practices; use of on-farm and third-

115 party processing facilities; and sourcing of livestock. On-farm processing refers to slaughter and

116 processing operations that are constructed on the farm where the broiler poultry are raised, and 
117 exclusively process the birds raised on that farm. Third-party processors refers to slaughter and

118 processing operations that process broiler poultry for a fee for other poultry producers. Other

119 information gathered using the survey questionnaire included county-level location data and

120 processor certification status under Maryland Department of Agriculture (MDA) or the United

121 States Department of Agriculture (USDA). Data from each survey questionnaire was matched to

122 a unique poultry sample's microbial outcome data. Information from the survey were used to

123 create categories for comparing microbial outcomes among different groups of vendors.

\section{Sample collection, transport and storage}

125 All 40 survey respondents provided oral consent to submit a single poultry meat sample from

126 their retail store for microbial analysis, and were recruited into the market-basket stage of this

127 research. Previous research indicated that frozen products were the most common products

128 marketed by this population [17]; only frozen products were obtained for microbial assessment.

129 Frozen poultry samples were transported by cooler and were not allowed to thaw during

130 transport to the laboratory freezer, where samples were stored at $-20^{\circ} \mathrm{C}$ to await microbial

131 culture.

132 Microbial culture and antimicrobial susceptibility testing methods: Salmonella spp.

133 Laboratory culture methods for Salmonella spp. were adapted from NARMS protocols for

134 culture-based methods for retail meat surveillance [19]. Packages of frozen meat were set out in

135 open coolers in the lab 12-16 hours in advance and allowed to warm to room temperature.

136 Thawed packages were opened aseptically using sterile surgical instruments, then two 25 gram

137 aliquots of surface muscle tissue, skin, and fat were removed aseptically, weighed and placed

138 into a stomacher bag containing either $200 \mathrm{ml}$ of double-strength lactose broth (Becton

139 Dickinson-Difco) or $200 \mathrm{ml}$ of $0.9 \%$ saline solution. Both aliquots were agitated and vigorously 
140 shaken for 60 seconds, then $15 \mathrm{ml}$ of the rinsate from the aliquot in the lactose broth was pipetted

141 into a sterile centrifuge tube, vortexed, and incubated overnight at $35^{\circ} \mathrm{C}$. Fifty milliliters of

142 rinsate was then pipetted from the aliquot in saline solution and vortexed with $50 \mathrm{ml}$ of double-

143 strength lactose broth in a sterile flask and the contents were mixed thoroughly. Fifteen

144 milliliters of this mixture was pipetted into a sterile centrifuge tube and incubated for 24 hours at

$14535^{\circ} \mathrm{C}$ with the tubes from the enrichment broth stomacher bag. From each tube, $0.1 \mathrm{ml}$ was

146 pipetted into $9.9 \mathrm{ml}$ of Rappaport-Vassiliadis medium (BD-Difco) and incubated for 16-20 hours

147 at $42^{\circ} \mathrm{C}$. One milliliter of these enrichment broths was transferred to $10 \mathrm{ml}$ tubes of pre-warmed

148 M-broth (BD-Difco) and incubated at $35^{\circ} \mathrm{C}$ for $6-8$ hours. The broth mixtures were allowed to

149 cool to room temperature and $10 \mu 1$ were streaked onto Xylose Lysine Deoxycholate (XLD) agar

150 plate (Becton-Dickinson) and incubated overnight at $35^{\circ} \mathrm{C}$. After 24 hours, plates were examined

151 for colonies typical for Salmonella growth (pink colonies with or without black centers). Any

152 typical colony was streaked to a trypticase soy agar plate supplemented with $5 \%$ defibrinated

153 sheep's blood (Thermo Scientific-Remel) to confirm isolate purity. Culture-positive isolates

154 were confirmed and tested for antimicrobial susceptibility using the BD Phoenix system. A list

155 of the antimicrobials tested is included in the supplement.

156 Microbial culture and antimicrobial susceptibility testing methods: E. coli

157 Laboratory culture methods for E. coli were adapted from standard food safety literature [19, 22,

$15823,24,25]$. Packages were allowed to thaw and opened as described above, and a 25 gram

159 aliquot of mixed tissue types was aseptically removed, weighed and placed in a sterile stomacher

160 bag with $200 \mathrm{~mL}$ of MacConkey enrichment broth (MAC broth) (Becton-Dickinson) and shaken

161 vigorously for 60 seconds. Fifteen milliliters of this rinsate was pipetted into a sterile centrifuge

162 tube and incubated $16-20$ hours at $35^{\circ} \mathrm{C}$. Tubes were vortexed thoroughly, and $10 \mu \mathrm{l}$ from each 
163 tube was streaked onto MacConkey agar (MAC agar) (Becton-Dickinson) plates, which were

164 incubated $16-20$ hours at $35^{\circ} \mathrm{C}$. Where E. coli-like growth (round pink colonies with or without a

165 dark center and a hazy area surrounding colonies) was observed, a single colony or a $1 \mu 1$ loop of

166 typical but overcrowded growth was streaked to a fresh MAC agar plate and incubated 16-20

167 hours at $35^{\circ} \mathrm{C}$. Culture-positive isolates were confirmed using the BD Phoenix automated

168 microbiology system for species identification and antimicrobial susceptibility testing [20, 21] at

169 the Johns Hopkins Hospital Clinical Diagnostic Microbiology Laboratory.

170 Microbial culture, antimicrobial susceptibility, and molecular testing methods: S. aureus

171 Laboratory culture methods for recovery of $S$. aureus isolates from poultry meat samples were

172 adapted from food safety literature on recovery of poultry livestock-associated S. aureus and

173 MDR-S. aureus [26, 27, 28]. Packages of meat were allowed to thaw and aseptically opened as

174 described above. A 25 gram aliquot of mixed tissue was removed, weighed and placed in a

175 stomacher bag with $200 \mathrm{ml}$ of Mueller-Hinton Broth (Becton Dickinson) supplemented with

$176 \quad 6.5 \% \mathrm{NaCl}(\mathrm{MHB}+)$. The bag was vigorously shaken for 60 seconds, then $15 \mathrm{ml}$ was pipetted to

177 a sterile centrifuge tube, vortexed, and incubated $16-20$ hours at $37^{\circ} \mathrm{C}$. Tubes were vortexed after

178 incubation and a $10 \mu l$ loop of enrichment broth was streaked to blood agar plates (Thermo

179 Scientific-Remel) and incubated 24 hours at $37^{\circ} \mathrm{C}$. Plates were examined for typical S. aureus

180 colonies (shiny, round, grey/white and with or without hemolysis) and either a single colony

181 (when present) or a $1 \mu$ l loop of typical growth was streaked to a Baird-Parker agar plate

182 (Becton-Dickinson) and incubated 24 hours at $37^{\circ} \mathrm{C}$. Plates were examined for typical growth of 183 coagulase-positive staphylococci (round, grey/black colonies demonstrating lecithinase activity)

184 and culture-positive samples were confirmed and tested for antimicrobial susceptibility using the

185 BD Phoenix system. A list of antimicrobials tested is included in the supplement. 
186 Molecular testing was preformed on presumptive staphylococcal isolates by PCR to confirm

187 presence of the S. aureus-specific nuclease gene (nuc) [29]. Additional PCR assays were used to

188 detect presence or absence the mec $\mathrm{A}$ or $m e c \mathrm{C}$ genes encoding methicillin resistance [30],

189 Panton-Valentine Leukocidin (PVL) genes $l u k F-P V$ and $l u k S-P V[31,32]$, and the

190 staphylococcal complement inhibitor (sch) gene [33]. Real-time quantitative fluorescence PCR

191 assay (TaqMan PCR) was used to detect genes encoding staphylococcal enterotoxins A, B, C,

192 and D (SEA, SEB, SEC, and SED) of S. aureus. [34]. Staphylococcal protein A (spa) typing was

193 performed using the Ridom Staph Type standard protocol (http://www.spaserver.ridom.de/) and

194 Eurofins Genomics sequencer (eurofinsgenomics.com).

195 Laboratory Quality Control

196 Quality control was assessed for laboratory bias or error by use of positive and negative controls.

197 Positive controls and laboratory blanks (uninoculated broth samples run through the culture

198 protocol) each were deployed at a rate of $10 \%$ for the culture protocols of all three target species

199 (4 blank samples and 4 ATCC-positive samples per species). ATCC 25922, ATCC 14028, and

200 ATCC 25923 were used as positive controls for E. coli, Salmonella spp. and S. aureus,

201 respectively.

202 Statistical Analysis

203 We used matched survey data obtained from the same sample population, derived variables from

204 these data and applied them to a regression analysis and a variety of nonparametric tests of

205 association to predict outcomes for microbial contamination and antimicrobial resistance.

206 Logistic regression and nonparametric tests were used to assess the strength and statistical

207 significance of any relationships between the variables derived from the survey data and the

208 binary outcomes associated with different measures of microbial contamination status. Simple 
209 and multiple logistic regression tests, along with non-parametric analyses were used to assess

210 inter-group differences between different categories of poultry vendors, as well as the effects of

211 freezing time on recovery of target microbes.

\section{2}

213

214

215

216

217

\section{Results}

\section{Enrollment and Recruitment}

Between October, 2014 and March, 2015 we identified and attempted to contact 93 potentiallyeligible participants. Sixteen potentially eligible participants identified using this system did not respond to two separate messages left on business phone voicemails. Sixteen other respondents informed us that their operation was currently out of business and 11 respondents reported that they were no longer marketing poultry meat as part of their business. From the remaining 50 eligible participants, four declined to participate in the study, citing privacy concerns, and six more participants were unable to schedule a time to participate during the recruitment window.

231 recruitment process participated in the study. This process is outlined in Figure 1. 
233 Responses to the survey questionnaire were recorded and analyzed. Demographic information

234 collected indicated that a majority (60\%) of participants were female and $100 \%$ were

235 white/Caucasian. Participants reported a median value of 5.5 years of professional experience,

236 with an interquartile range of 2.5-10.0 years of experience. Figure 2 shows the geographic

237 distribution of participating poultry farms at the county level across the state. Table 1 contains

238 information on the scale of poultry production and on-farm practices among survey respondents,

239 with most respondents indicating that they practiced on-farm poultry processing with a median

240 flock size of 1,050 birds per year. Figures 3-6 summarize survey responses on the number and

241 variety of other livestock and companion animals living on the same property as the poultry

242 flocks. The vast majority of poultry production among respondents occurs in settings where

243 poultry interact with and share a living environment with other livestock and companion animal

244 species. Table 2 describes the sanitation and disinfection practices employed by respondents

245 using on-farm poultry processing systems, indicating that a large majority of participants use two

246 or more methods of disinfection both before and after a run of poultry slaughter and processing.

247 A minority (17.5\%) of respondents reported using pharmaceutical antimicrobial inputs in poultry

248 production. Among the 7/40 participants who used these inputs, three reported using antibiotics

249 only to therapeutically treat sick livestock; all three reported exclusively using tetracycline

250 administered through drinking water. The remaining four participants all reported preventative

251 usage limited to recently-arrived chicks, who receive feed supplemented with coccidiostat drugs,

252 and are put onto non-medicated feed for the "grow-out" period of production (from between 2-3

253 weeks to when the birds reach slaughter weight at $\sim 7-12$ weeks of age). Coccidiostats were the

254 only antimicrobial inputs for which respondents reported prophylactic use. 
Prevalence and antimicrobial susceptibility of Gram-negative target species (E. coli, Salmonella

256 spp.)

257 E. coli was recovered from $9 / 40(22.5 \%)$ of retail poultry samples. Among the nine confirmed

258 isolates, two were resistant to one class of antimicrobials; one isolate was resistant to tetracycline

259 and the other to imipenem, a beta-lactam/carbapenem antibiotic. No E. coli isolates were

260 resistant to more than one class of antimicrobials. Prevalence and antimicrobial-resistance

261 phenotypes of $E$. coli among retail meat samples purchased from different categories of direct-

262 market vendors is included in Table 3. Results comparing prevalence rates of AMR phenotypes

263 among E. coli isolates recovered from 2014 NARMS surveillance in Maryland to the market-

264 basket samples in this study are displayed in Table 4. No positive Salmonella isolates were

265 recovered from any of the retail poultry samples analyzed in this study. The dual culture

266 protocols that used either a lactose enrichment broth or $0.9 \%$ saline media as an initial aliquot

267 did not yield differential results.

Microbial prevalence and antimicrobial susceptibility of Gram-positive target species ( $S$.

270 S. aureus was recovered from $12 / 40$ (30\%) of poultry samples. Of the 12 positive isolates, 6/12

271 were resistant to one or more antimicrobial classes, $1 / 12$ were resistant to two antimicrobial

272 classes, and none were resistant to three or more antimicrobials. All AMR S. aureus were

273 exclusively resistant to tetracycline, penicillin and/or ampicillin. No multi-drug resistant $S$.

274 aureus or methicillin-resistant $S$. aureus were recovered, and no mecA or mec $C$ genes were

275 detected. Four isolates were positive for the scn gene, which is a potential marker of human

276 (rather than animal) origin. The $p v l$ gene was not detected in any samples. No staphylococcal

277 enterotoxin (SE) genes were detected in any samples. Eight unique spa-types where identified

278 across the 16 isolates tested. The AMR phenotypes of all S. aureus recovered from poultry 
279 samples are displayed along different categories of direct-market vendors in Table 3 and in the

280 heat map in Table 5.

\section{Sample freezing time and regression analysis}

282 Data used to calculate the duration of time between when the poultry carcass was processed and

283 frozen and when the samples was thawed for analysis was available for 30/40 samples. For the

284 remaining 10 samples this information was not on the label and could not be estimated

285 accurately by the vendor. The samples had been frozen for an average of 140 days, with a range

286 of 54-260 days and an interquartile range (IQR) of 108-150 days. Freezing time was treated as a

287 continuous predictor variable for a simple logistic regression analysis for the outcome of finding

288 any contamination, was used to determine a trend-level $(p=0.08)$ increase in the odds ratio of

289 finding any contamination with a one-day increase in freezing time (1.02, 95\% CI: 0.99-1.04).

290 This value was lower (1.01, 95\% CI: 0.99-1.02) and the association was weaker $(\mathrm{p}=0.14)$ when

291 the microbial outcome was limited to S. aureus-positive samples. When 10-day increases in

292 freezing time were used to create an ordinal predictor variable for recovery of any target

293 microorganisms, there were only slight changes to the observed association (1.04, 95\% CI: $0.94-$

$2942.09)$ and the association was not statistically significant at $\alpha=0.05(\mathrm{p}=0.09)$. When 30 -day

295 increases in freezing time was used as an ordinal predictor variable for the same outcome, a

296 stronger signal (1.86, 95\% CI: 0.82-4.17) was observed, but this association was not statistically

297 significant at $\alpha=0.05(\mathrm{p}=0.09)$. 


\section{Discussion}

302

303

304

305

306

307

308

309

310

311

312

313

314

315

316

317

Survey Results

318 The survey data presented here quantify the frequency and characterize the distribution of

319 structural elements and workplace practices of direct-market poultry operations that had been

320 previously identified by research carried out in this population as important or relevant to

321 microbial food safety [17]. Antimicrobial input usage was very low among participants; what

322 usage was reported occurred under different conditions than those understood to drive the 
323 propagation of MDR foodborne pathogens in the industrial poultry supply chain. Only $10 \%$ of

324 respondents from the direct-market supply chain reported use of antimicrobial inputs for disease

325 prophylaxis in poultry flocks. Moreover, the antimicrobial inputs used by these respondents

326 included only a single coccidiostat. Further, the antimicrobial mechanism associated with this

327 drug is understood to be only weakly (if at all) associated with acquired AMR in bacterial

328 populations [38]. None of the observed AMR phenotypes in our sample occurred in the samples

329 from survey respondents reporting use of antimicrobial inputs for disease prophylaxis in their

330 poultry flocks.

331 Prevalence and AMR of target pathogens

332 The absence of MDR E. coli or S. aureus is a finding of particular public health significance.

333 These results are strong supporting evidence for the hypothesis that some of the characteristics of

334 direct-market poultry production may correlate with much lower prevalence of detection of drug-

335 resistant E. coli on consumer poultry meat products $(5 \%)$ compared to products from industrial

336 poultry production (77.1\%), based on NARMS surveillance data limited to poultry meat

337 purchased in Maryland in 2014. S. aureus is not assessed routinely via NARMS surveillance

338 [39].

339 The observed prevalence of $S$. aureus (32.5\%) in this market-basket sample of Maryland direct-

340 market retail poultry is roughly equivalent to trends observed in the few market-basket studies

341 assessing the industrial poultry supply chain. This indicates that $S$. aureus is likely to still be a

342 relevant food safety concern for direct-market poultry production. However, the absence of

343 MDR S. aureus presents a major potential difference in the overall food safety health risks

344 associated with this supply chain. 
345 The absence of Salmonella positive isolates among the market-basket samples is surprising. Our

346 negative results do not necessarily indicate an absence of viable Salmonella on these samples or

347 within this supply chain. We can identify three possibilities that may explain these findings: (1)

348 Salmonella concentrations were below the LOD of our methods; (2) freezing poultry reduced the

349 viable number of Salmonella; (3) viable Salmonella isolates were present, but were injured or

350 metabolically damaged by freezing and did not grow on selective culture media.

351 The rates of E. coli contamination are substantially lower than those reported in NARMS and in

352 other research literature. In $2015,63.5 \%$ of retail poultry meat samples sampled under NARMS

353 surveillance were positive for E. coli contamination, similar to recovery of E. coli the prior year

354 [39]. This may indicate a difference in food safety risks for consumers of direct-market products

355 to be infected with fecal-origin bacterial contaminants, but more research is needed to establish

356 the validity of those findings. As with Salmonella, freezing may play a role in reduction of $E$.

357 coli recovered using these methods. Research on this topic within the industrial poultry supply

358 chain has been limited and inconclusive as to whether different methods of freezing result in

359 significant reductions in viable and recoverable Salmonella spp. and E.coli [40, 41].

360 Strengths, limitations and areas for further research

361 One strength is of the study is having a mixed-methods approach that included both microbial

362 sampling and survey interviews with participants. A second strength is that, while the study

363 population was small, it captured $\sim 60 \%$ of the population of direct-market poultry producers in

364 Maryland and therefore these findings likely are generalizable to the entire population of

365 Maryland producers.

366 There are several limitations, one being the sample size $(\mathrm{N}=40)$, which is small for a multiple

367 logistic regression analysis. A second limitation was the cross-sectional study design—repeated 
samples would improve our ability to assess prevalence of microbial pathogens in the statewide

369 direct market supply chain. Further, this study did not conduct serovar analysis of E. coli isolates

370 or collect data to determine pathogenicity. In contrast, S. aureus isolates were tested for several

371 characteristics related to pathogenicity, including presence of common enterotoxin genes linked

372 to foodborne intoxication. In particular, sampling only frozen poultry samples presents both

373 strengths and limitations to our analysis. Frozen poultry is the product form that consumers

374 would purchase; however, freezing may affect target pathogen recovery. Fresh poultry products

375 constitute the majority of samples in market-basket studies of the industrial poultry supply chain,

376 which limits our ability to compare directly with these studies. Future research on this topic

377 should address these limitations and seek to differentiate between pathogenic and non-

378 pathogenic $E$. coli contamination of market-basket products, and consider to include additional

379 poultry-associated foodborne indicator bacteria and pathogens, such as Enterococcus and

380 Campylobacter.

381 This research is an important step to characterize the microbial food safety of food products from

382 direct market poultry, which is an alternative to conventional poultry supply chains sold in

383 supermarkets. These data provide evidence to support the potential for management practices

384 that limit antimicrobial inputs to be associated with lower recovery of drug-resistant indicator

385 bacteria and pathogens. These findings provide a baseline for future research on direct-to-

386 consumer poultry products in Maryland and beyond, and may inform larger efforts to describe

387 the contribution of food animal production to the global burden of drug-resistant pathogens.

388 Acknowledgements: This research was carried out with laboratory support from Dr. Karen C.

389 Carroll, MD and the Medical Microbiology laboratory at Johns Hopkins Hospital for microbial

390 isolate analysis using the BD Phoenix automated microbiology system for species identification 
391 and antimicrobial susceptibility testing. Funding from the Johns Hopkins Center for a Livable

392 Future's Fellowship program supported this study. The funders had no role in study design, data

393 collection and interpretation, or the decision to submit the work for publication. Dr. Christopher

394 Heaney served as primary advisor to this project.

395

396

397

398

399

400

401

402

403

404

405

406

407 


\section{References}

410 [1] Centers for Disease Control and Prevention: 2011 Estimates of foodborne illness in the 411 United States. April, 2014; accessed May 10, 2015: www.cdc.gov/foodborneburden/2011-

412 foodborne-estimates.html

413 [2] Centers for Disease Control and Prevention: Incidence and Trends of Infection with 414 Pathogens Transmitted Commonly Through Food - Foodborne Diseases Active Surveillance 415 Network, 10 U.S. Sites, 2006-2013. MMWR April, 2014. 63(15);328-332

416 [3] Centers for Disease Control and Prevention: FoodNet 2012 Surveillance Report. (Final 417 Report). Atlanta, Georgia: U.S. Department of Health and Human Services, CDC. 2014

418 [4] Painter JA, Hoekstra RM, Ayers T, Tauxe RV, Braden CR, Angulo FJ, Griffin PM: 419 Attribution of foodborne illnesses, hospitalizations, and deaths to food commodities by using 420 outbreak data, United States, 1998-2008. Emerging Infectious Disease. 2013 Mar;19(3):407-15

421 [5] Perry JA, Wright GD: Forces shaping the antibiotic resistome. Bioessays. 2014

422 Dec;36(12):1179-84

423 [6] Looft T, Johnson TA, Allen HK, Bayles DO, Alt DP, Stedtfeld RD, Sul WJ, Stedtfeld TM, 424 Chai B, Cole JR, Hashsham SA, Tiedje JM, Stanton TB: In-feed antibiotic effects on the swine microbiome. Proceedings of the National Academy of Science USA. 2012 Jan 31;109(5):1691-6

[7] Price LB, Stegger M, Hasman H, Aziz M, Larsen J, Andersen PS, Pearson T, Waters AE, Foster JT, Schupp J, Gillece J, Driebe E, Liu CM, Springer B, Zdovc I, Battisti A, Franco A, Zmudzki J, Schwarz S, Butaye P, Jouy E, Pomba C, Porrero MC, Ruimy R, Smith TC, Robinson DA, Weese JS, Arriola CS, Yu F, Laurent F, Keim P, Skov R, Aarestrup FM: Staphylococcus aureus CC398: host adaptation and emergence of methicillin resistance in livestock. MBio. 2012 431 Feb 21;3(1)

432 [8] Love DC, Davis MF, Bassett A, Gunther A, Nachman KE: Dose imprecision and resistance: 433 free-choice medicated feeds in industrial food animal production in the United States.

434 Environmental Health Perspectives. 2011 Mar;119(3):279-83

435 [9] Witte W: Selective pressure by antibiotic use in livestock. International Journal of 436 Antimicrobial Agents. 2000 Nov;16 Suppl 1:S19-24

437 [10] United States Department of Health and Human Services, CDC News Release: Antibiotic 438 resistance in foodborne germs is an ongoing threat. (last updated July, 2014). Accessed May 10, 439 2015: http://www.cdc.gov/media/releases/2014/p0701-antibiotic-resistance.html

440 [11] Centers for Disease Control and Prevention: Antibiotic Resistance Threats in the United 441 States, 2013. Atlanta, Georgia: U.S. Department of Health and Human Services, CDC. 2014

442 [12] Rothrock MJ Jr, Fan P, Jeong KC, Kim SA, Ricke SC, Park SH. Complete Genome 443 Sequence of Listeria monocytogenes Strain MR310, Isolated from a Pastured-Flock Poultry 
444 Farm System. Genome Announcements-American Society for Microbiology. 2018 Mar 445 8;6(10). pii: e00171-18.

446 [13] Dailey N, Niemeier D, Elkhoraibi C, Sentíes-Cué CG, Pitesky M. Descriptive survey and Salmonella surveillance of pastured poultry layer farms in California. Poultry Science. 2017 Apr $448 \quad 1 ; 96(4): 957-965$

449 [14] Melendez SN, Hanning I, Han J, Nayak R, Clement AR, Wooming A, Hererra P, Jones FT, Foley SL, Ricke SC: Salmonella enterica isolates from pasture-raised poultry exhibit antimicrobial resistance and class I integrons. Journal of Applied Microbiology. 2010

452 Dec;109(6):1957-66

453 [15] Trimble LM, Alali WQ, Gibson KE, Ricke SC, Crandall P, Jaroni D, Berrang M, 454 Habteselassie MY: Prevalence and concentration of Salmonella and Campylobacter in the 455 processing environment of small-scale pastured broiler farms. Poultry Science. 2013 456 Nov;92(11):3060-6.

[16] Scheinberg J, Doores S, Cutter C: A microbiological comparison of poultry products obtained from farmers' markets and supermarkets in Pennsylvania. Journal of Food Safety. 2013

$460 \quad$ (33)259-264

[17] Baron P, Frattaroli S: Awareness and Perceptions of Food Safety Risks and Risk Management in Poultry Production and Slaughter: A Qualitative Study of Direct-Market Poultry Producers in Maryland. 2016 June; PLoS ONE 11(6): e0158412.

[18] Sadler GR, Lee H, Lim R, Fullerton J: Research Article: Recruitment of hard-to-reach population subgroups via adaptations of the snowball sampling strategy. Nursing and Health

468 [19] United States Food and Drug Administration: National Antimicrobial Resistance Monitoring System Retail Meat Final Report, 2012. April, 2014. Accessed May 10, 2015 : alAntimicrobialResistanceMonitoringSystem/UCM442212.pdf of the BD Phoenix automated microbiology system for identification and antimicrobial susceptibility testing of staphylococci and enterococci. Journal of Clinical Microbiology. 2006

476 [21] Carroll KC, Glanz BD, Borek AP, Burger C, Bhally HS, Henciak S, Flayhart D: Evaluation 477 of the BD Phoenix automated microbiology system for identification and antimicrobial 478 susceptibility testing of Enterobacteriaceae. Journal of Clinical Microbiology. 2006 479 Oct;44(10):3506-9

480 [22] Gill A, Huszczynski G, Gauthier M, Blais B: Evaluation of eight agar media for the 481 isolation of shiga toxin-Producing Escherichia coli. Journal of Microbiology Methods. 2014 482 Jan;96:6-11 
[23] Rajkowski KT, Rice EW: Growth and recovery of selected gram-negative bacteria in reconditioned wastewater. Journal of Food Protection. 2001 Nov;64(11):1761-7 reconditioned pork-processing wastewater. Journal of Food Protection. 1999 Jul;62(7):731-4.

[25] De Boer E, Heuvelink AE: Methods for the detection and isolation of Shiga toxin-producing Escherichia coli. Symposium Series (Society for Applied Microbiology). 2000;(29):133S-143S

[26] Waters AE, Contente-Cuomo T, Buchhagen J, Liu CM, Watson L, Pearce K, Foster JT, Bowers J, Driebe EM, Engelthaler DM, Keim PS, Price LB: Multidrug-Resistant Staphylococcus aureus in US Meat and Poultry. Clinical Infectious Diseases. 2011 May;52(10):1227-30. high-throughput poultry slaughtering facility. Journal of Food Protection. 2013 Mar;76(3):413-9

[28] de Boer E, Zwartkruis-Nahuis JT, Wit B, Huijsdens XW, de Neeling AJ, Bosch T, van Oosterom RA, Vila A, Heuvelink AE: Prevalence of methicillin-resistant Staphylococcus aureus in meat. International Journal of Food Microbiology. 2009 Aug 31;134(1-2):52-6

[29] Sasaki T, Tsubakishita S, Tanaka Y, Sakusabe A, Ohtsuka M, Hirotaki S, Kawakami T, Fukata T, Hiramatsu K. Multiplex-PCR method for species identification of coagulase-positive staphylococci. Journal of Clinical Microbiology. 2010 Mar;48(3):765-9 Brooks K, Pickard DJ, Teale C, Parkhill J, Bentley SD, Edwards GF, Girvan EK, Kearns AM, Pichon B, Hill RL, Larsen AR, Skov RL, Peacock SJ, Maskell DJ, Holmes MA. Methicillinresistant Staphylococcus aureus with a novel mecA homologue in human and bovine populations in the UK and Denmark: a descriptive study. Lancet Journal of Infectious Disease. 2011 Aug;11(8):595-603. PCR assay for detection of the staphylococcal virulence marker Panton-Valentine leukocidin genes and simultaneous discrimination of methicillin-susceptible from -resistant staphylococci. Journal of Clinical Microbiology. 2006 Mar;44(3):1141-4. aureus USA400 sibling strains in a large Canadian health-care region. The Journal of Infectious Diseases. 2008 Jan 15;197(2):195-204.

[33] van Wamel WJ, Rooijakkers SH, Ruyken M, van Kessel KP, van Strijp JA. The innate immune modulators staphylococcal complement inhibitor and chemotaxis inhibitory protein of Staphylococcus aureus are located on beta-hemolysin-converting bacteriophages. Journal of Bacteriology. 2006 Feb;188(4):1310-5. 
[34] Klotz M, Opper S, Heeg K, Zimmermann S. Detection of Staphylococcus aureus enterotoxins A to D by real-time fluorescence PCR assay. Journal of Clinical Microbiology 2003 Oct;41(10):4683-7.

[35] National Antimicrobial Resistance Monitoring System (NARMS) Animal NARMS Data (2017) https://www.fda.gov/AnimalVeterinary/SafetyHealth/AntimicrobialResistance/NationalAntimicr obialResistanceMonitoringSystem/ucm416741.htm

[36] Thapaliya D, Forshey BM, Kadariya J, Quick MK, Farina S, O' Brien A, Nair R, Nworie A, Hanson B, Kates A, Wardyn S, Smith TC. Prevalence and molecular characterization of Staphylococcus aureus in commercially available meat over a one-year period in Iowa, USA. Journal of Food Microbiology. 2017 Aug;65:122-129. the United States, 2002 to 2014. Applied Environmental Microbiology. 2017 Dec 15;84(1). 1902-17

[38] Opinion of the the Panel on Animal Feed of the Norwegian Scientific Committee for Food Safety. The risk of development of antimicrobial resistance with the use of coccidiostats in poultry diets. VKM. (2015) ISBN: 978-82-8259-185-0, Oslo, Norway.

[39] National Antimicrobial Resistance Monitoring System: NARMS Integrated Report, 2015. Laurel, MD: U.S. Department of Health and Human Services, FDA, 2017. ML, Calvo J, Howell M, Corry JE: Decontamination of poultry carcasses using steam or hot water in combination with rapid cooling, chilling or freezing of carcass surfaces. International Escherichia coli and Salmonella Typhimurium on the surface of raw poultry products subjected to crust freezing. Journal of Poultry Science (2011) 90 (12): 2874-2878 
561 Tables and Figures

Figure 1: Flowchart for Enrollment and Recruitment of Participants

\begin{tabular}{|c|c|c|c|c|}
\hline $\begin{array}{c}\text { All Farms } \\
\text { Contacted } \\
\quad \mathrm{N}=93\end{array}$ & $\begin{array}{l}\text { Not in } \\
\text { business } \\
\mathrm{N}=27\end{array}$ & $\begin{array}{c}\text { No } \\
\text { Response } \\
\mathrm{N}=16\end{array}$ & $\begin{array}{l}\text { No time or } \\
\text { privacy } \\
\text { concerns } \\
\mathrm{N}=10\end{array}$ & $\begin{array}{c}\text { Farms } \\
\text { Included } \\
\mathrm{N}=40\end{array}$ \\
\hline
\end{tabular}

563 Figure 2: Geographic Distribution of Participating Poultry Producers in Maryland Counties

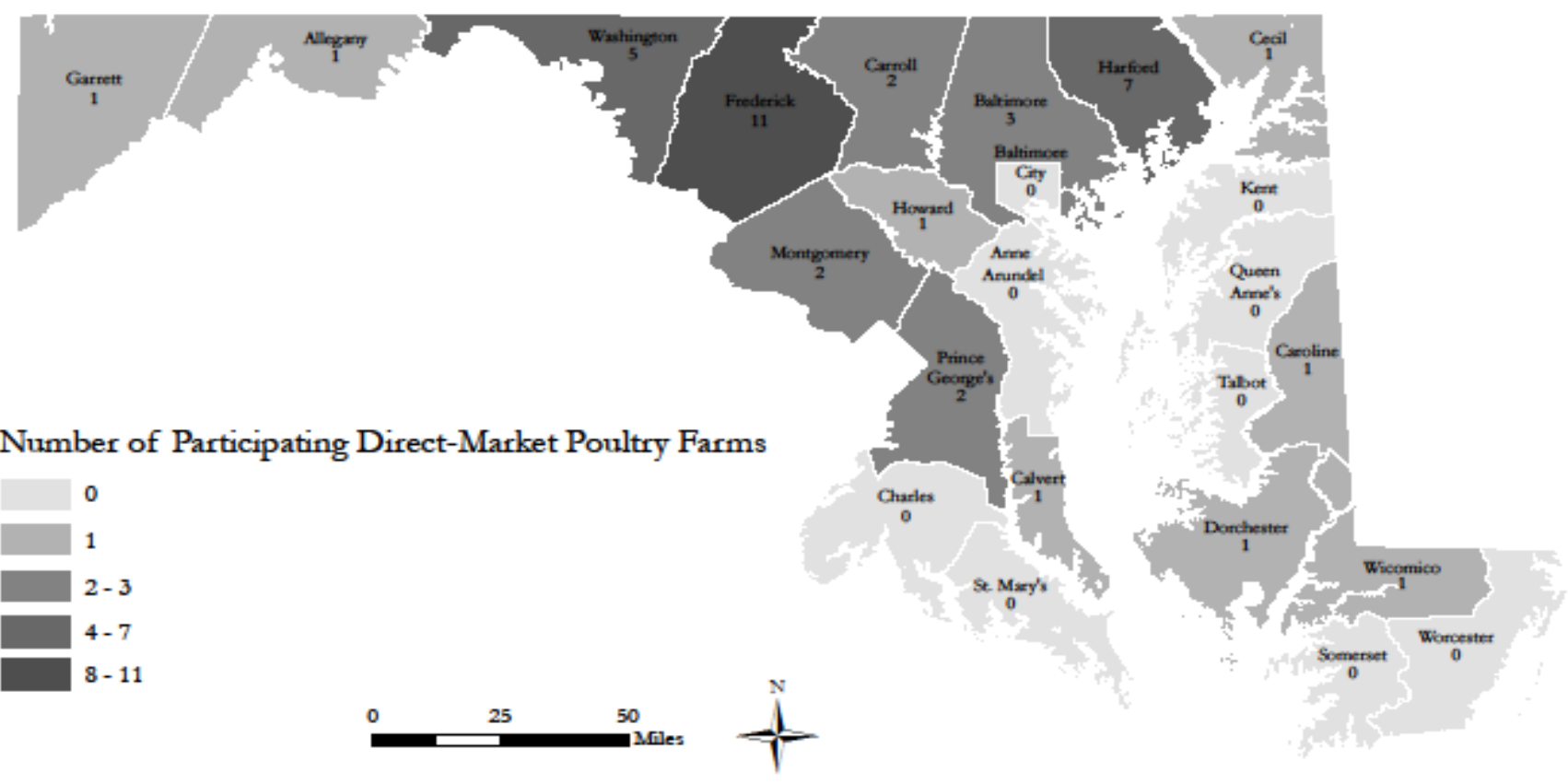


bioRxiv preprint doi: https://doi org/10.1101/643106: this version posted May 20 2019. The copyright holder for this preprint (which was not certified by peer review) is the author/funder, who has granted bioRxiv a license to display the preprint in perpetuity. It is made available under aCC-BY-ND 4.0 International license.

579 Figure 3: Percent of Participating Broiler Poultry Farms Keeping Other Livestock on Premises, By 580 Type of Livestock

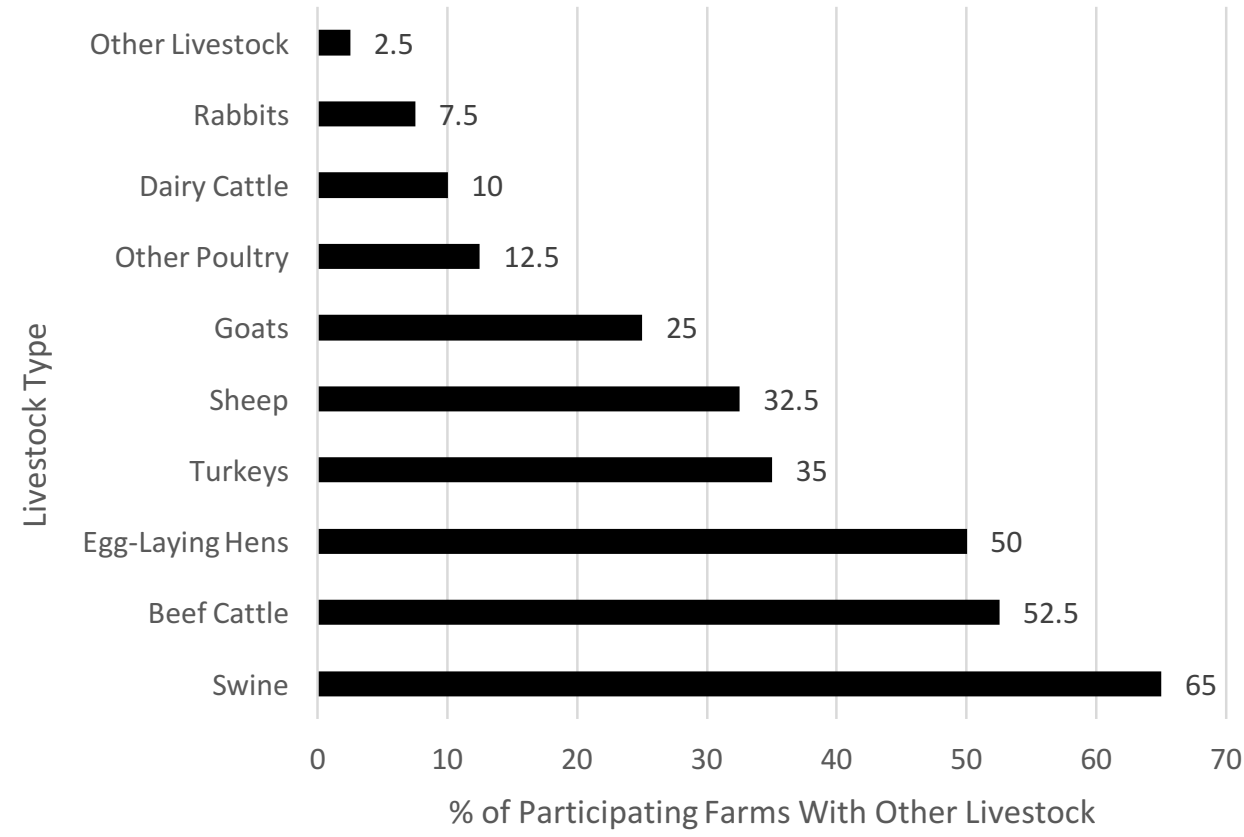

582 Figure 4: Percent of Participating Broiler Poultry Farms Keeping Pets on Premises, By Type of Pet

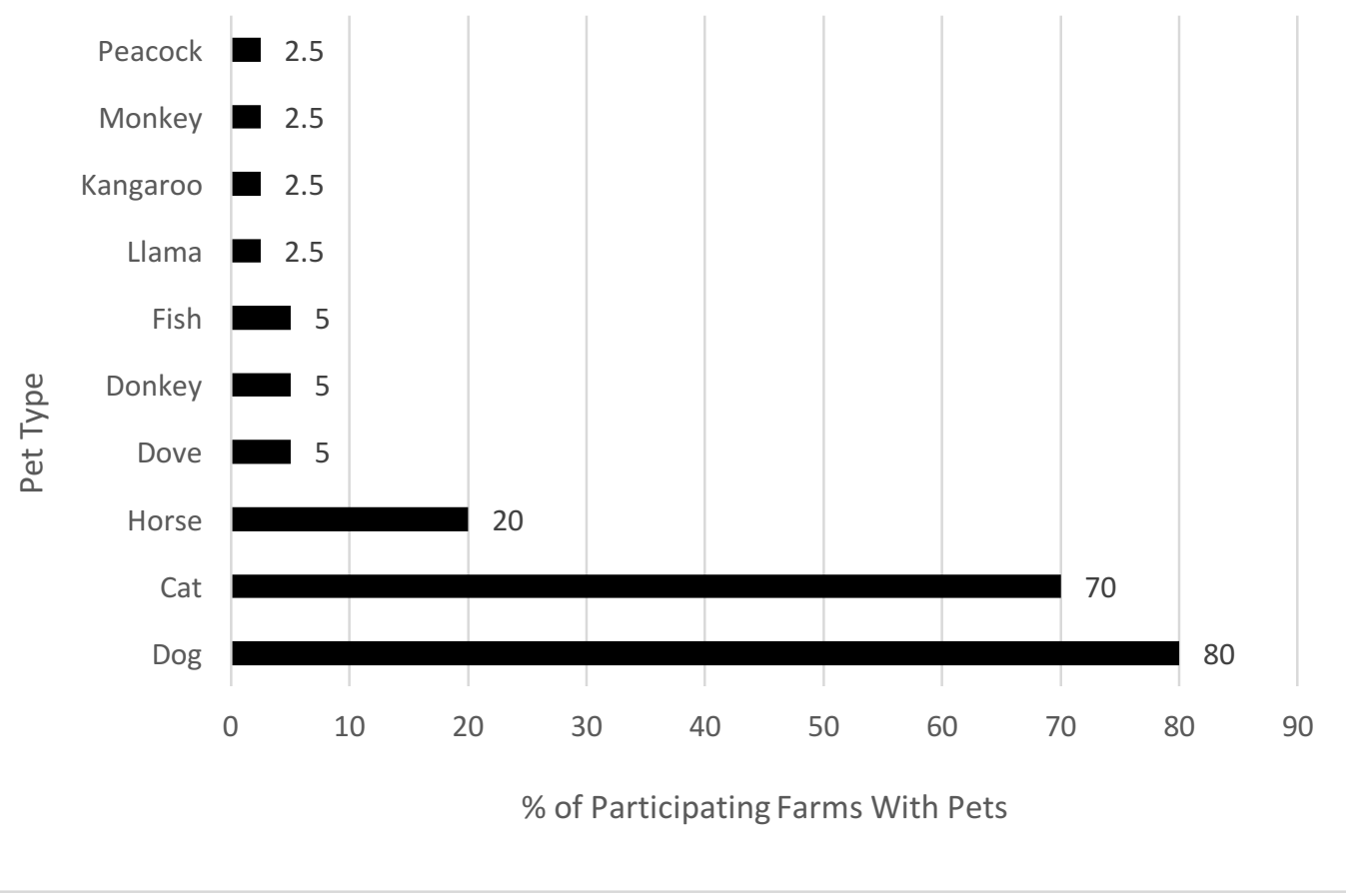


585 Figure 5: Percent of Participating Farms With Non-Broiler Poultry Livestock Species on Premises,

586 by Number of Other Species

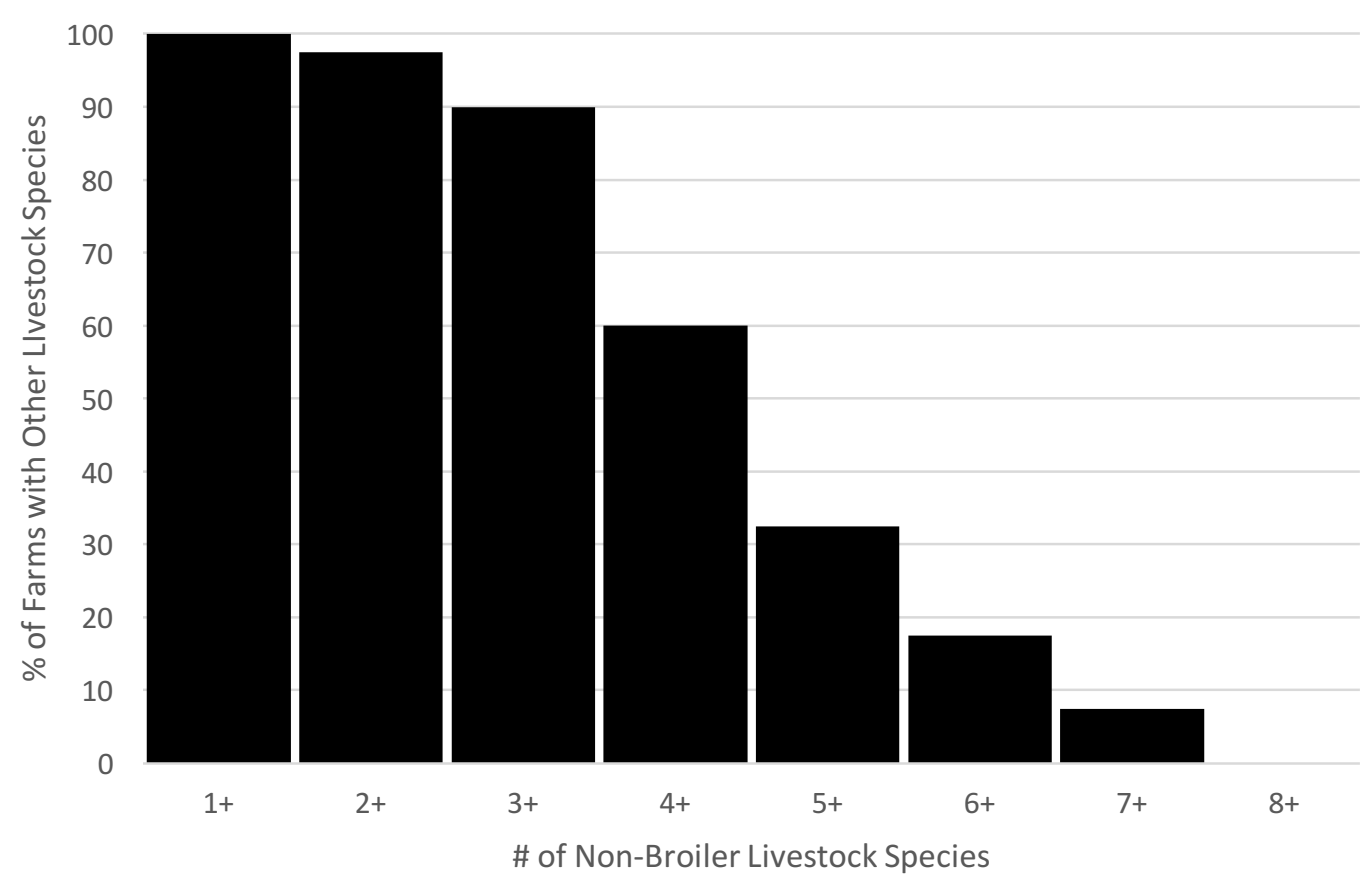

588 Figure 6: Percent of Participating Farms With Pets on Premises, by Number of Pet Species

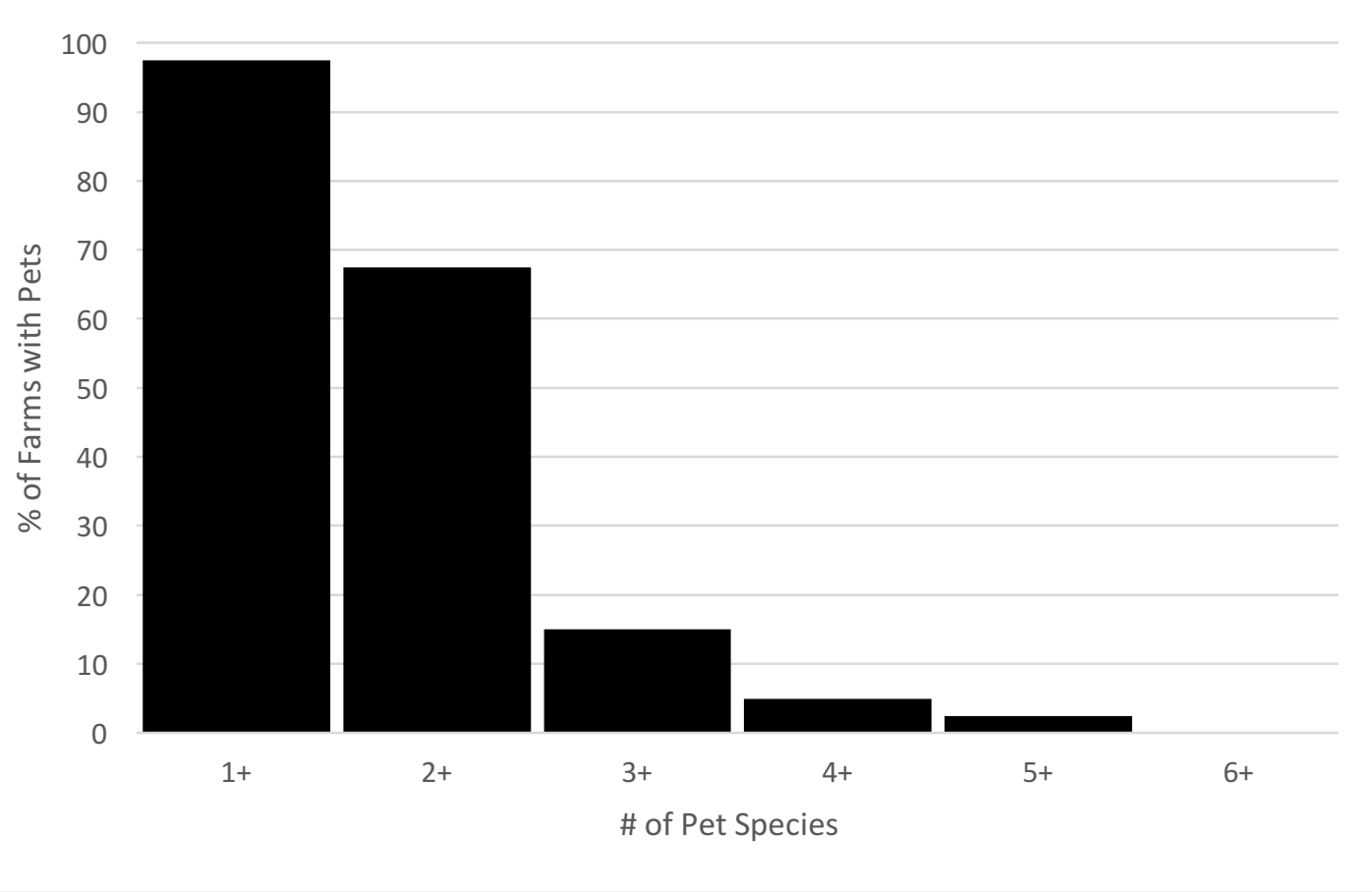


Table 1: Production Scale of Maryland Direct-Market Poultry Operations

\begin{tabular}{|c|c|c|c|c|c|c|c|}
\hline \multirow{2}{*}{ Flock size } & \multirow{2}{*}{$\begin{array}{c}\text { Total } \\
(\mathrm{N}=40)\end{array}$} & \multicolumn{3}{|c|}{ On-Farm Processing } & \multicolumn{3}{c|}{$\begin{array}{c}\text { Third-Party Processing } \\
(\mathrm{N}=25)\end{array}$} \\
\cline { 3 - 8 } & $\begin{array}{c}\mathrm{USDA}^{\mathrm{a}} \\
(\mathrm{N}=1)\end{array}$ & $\begin{array}{c}\mathrm{MDA}^{\mathrm{b}} \\
(\mathrm{N}=18)\end{array}$ & $\begin{array}{c}\text { Neither } \\
(\mathrm{N}=6)\end{array}$ & $\begin{array}{c}\text { USDA } \\
(\mathrm{N}=11)\end{array}$ & $\begin{array}{c}\text { MDA } \\
(\mathrm{N}=3)\end{array}$ & $\begin{array}{c}\text { Neither } \\
(\mathrm{N}=1)\end{array}$ \\
\hline $\begin{array}{c}\text { Median }\left(\mathrm{IQR}^{\mathrm{c}}\right) \\
\text { Birds/yr }\end{array}$ & $\begin{array}{c}1,050 \\
(450-1,700)\end{array}$ & $\begin{array}{c}2,700 \\
(2,700)\end{array}$ & $\begin{array}{c}1,200 \\
(800-2,500)\end{array}$ & $\begin{array}{c}800 \\
(200-1,700)\end{array}$ & $\begin{array}{c}800 \\
(400-1,200)\end{array}$ & $\begin{array}{c}250 \\
(150-800)\end{array}$ & $\begin{array}{c}2,000 \\
(2,000)\end{array}$ \\
\hline $\begin{array}{c}\text { Median }\left(\mathrm{IQR}^{\mathrm{c}}\right) \\
\text { Flock Size }\end{array}$ & $\begin{array}{c}100 \\
(50-150)\end{array}$ & $\begin{array}{c}200 \\
(200-200)\end{array}$ & $\begin{array}{c}70 \\
(50-100)\end{array}$ & $\begin{array}{c}33.5 \\
(30-40)\end{array}$ & $\begin{array}{c}150 \\
(100-175)\end{array}$ & $\begin{array}{c}100 \\
(50-150)\end{array}$ & $\begin{array}{c}500 \\
(500)\end{array}$ \\
\hline
\end{tabular}

a: USDA: United States Department of Agriculture Food Safety Inspection Service Certified Food Animal Processor

b: MDA: Maryland Department of Agriculture Food Safety Certified Food Animal Processor

c: IQR: Inter-Quartile Range

Table 2: Disinfection Practices of Participating OFPP Facilities, By Processing Stage (N=25)

\begin{tabular}{|c|c|c|c|}
\hline & Pre-Processing (\%) & During Processing (\%) & Post-Processing (\%) \\
\hline Any Disinfection & $100 \%$ & $44 \%$ & $100 \%$ \\
\hline Bleach Solution & $84 \%$ & $24 \%$ & $76 \%$ \\
\hline Soap Water & $72 \%$ & $16 \%$ & $48 \%$ \\
\hline Hot Water & $12 \%$ & $4 \%$ & $16 \%$ \\
\hline $\begin{array}{c}\text { Vinegar/Peroxide } \\
\text { UV (Sunlight) }\end{array}$ & $12 \%$ & $4 \%$ & $8 \%$ \\
\hline $\begin{array}{c}\text { No Soap, No } \\
\text { Bleach }\end{array}$ & $4 \%$ & $76 \%$ & $16 \%$ \\
\hline $\begin{array}{c}\text { 2+ Cleaning } \\
\text { Agents }\end{array}$ & $76 \%$ & $16 \%$ & $64 \%$ \\
\hline
\end{tabular}


Table 3: Prevalence of AMR S. aureus and E. coli Isolates by Processor Location (on-farm vs. third party facility) and Food Safety Agency Inspection Status

\begin{tabular}{|c|c|c|c|c|c|}
\hline Processor Type & S. aureus & $\begin{array}{c}\text { S. aureus: } \\
\text { 1+ Classes } \\
\text { AMR }\end{array}$ & $\begin{array}{c}\text { S. aureus: } \\
2 \text { Classes } \\
\text { AMR }\end{array}$ & E. coli & $\begin{array}{c}\text { E. coli: } \\
\text { 1 Class AMR }\end{array}$ \\
\hline $\begin{array}{l}\text { All Processors } \\
\qquad(\mathrm{n}=40)\end{array}$ & $30 \%$ & $15 \%$ & $2.5 \%$ & $22.5 \%$ & $5 \%$ \\
\hline 3 rd Party ${ }^{a}(n=15)$ & $33.3 \%$ & $13.3 \%$ & $6.7 \%$ & $26.7 \%$ & $6.7 \%$ \\
\hline $\begin{array}{l}\text { OFPP: All } \\
(n=25)\end{array}$ & $28 \%$ & $16 \%$ & $0 \%$ & $20 \%$ & $4 \%$ \\
\hline $\begin{array}{l}\text { OFPP: }{ }^{\text {MDA/USDA }}{ }^{\mathrm{c}} \\
(\mathrm{n}=19)\end{array}$ & $21.1 \%$ & $15.8 \%$ & $0 \%$ & $26.3 \%$ & $5.3 \%$ \\
\hline OFPP: Uncertified ${ }^{d}(n=6)$ & $33.3 \%$ & $16.7 \%$ & $0 \%$ & $0 \%$ & $0 \%$ \\
\hline
\end{tabular}


Table 4: Prevalence of AMR in E. coli Isolates by Processor Location and Inspection Status from Sample Data Compared to 2014 Market-Basket Data from NARMS Surveillance in Maryland

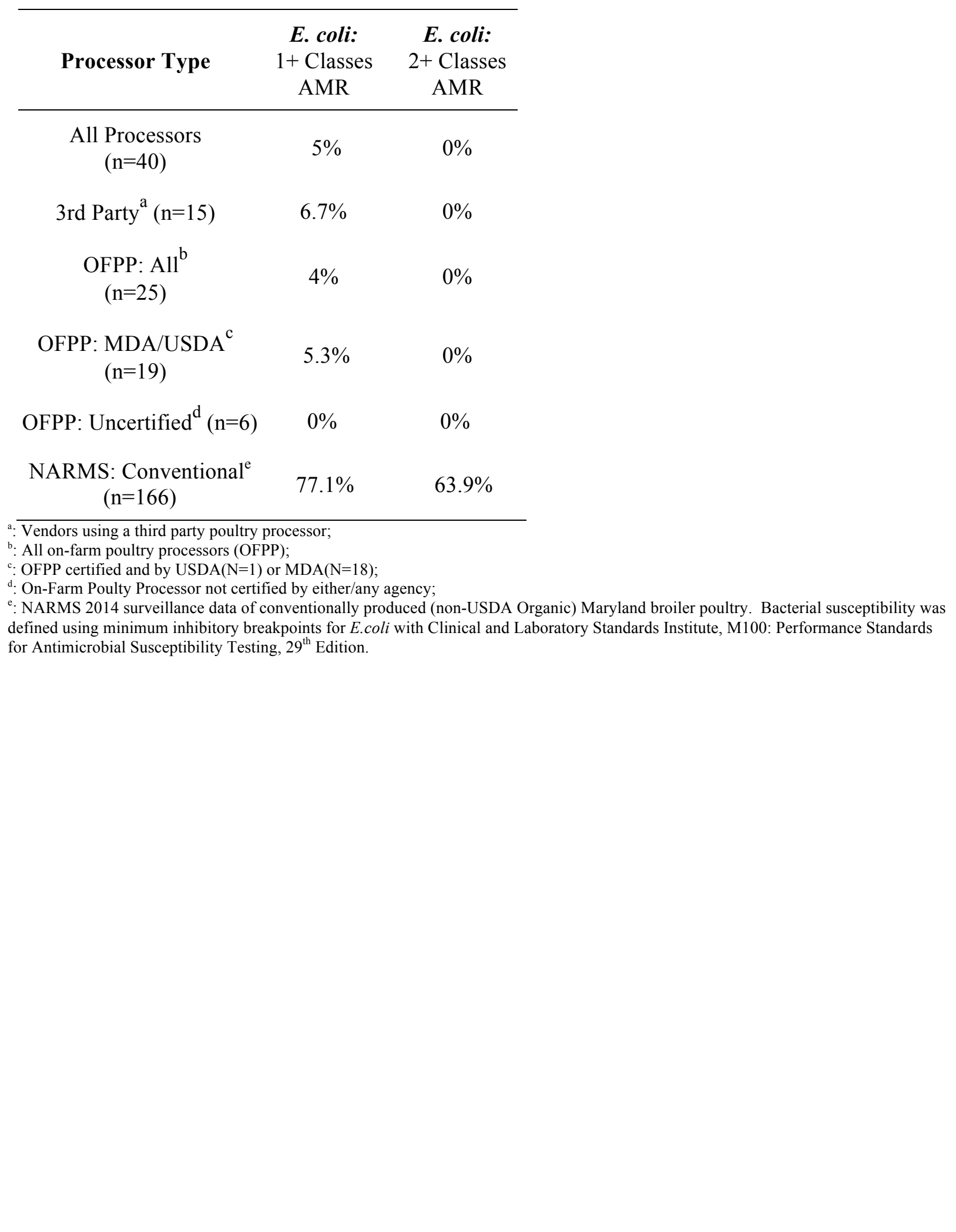


bioRxiv preprint doi: https://doi.org/10.1101/643106; this version posted May 20, 2019. The copyright holder for this preprint (which was not certified by peer review) is the author/funder, who has granted bioRxiv a license to display the preprint in perpetuity. It is made available under aCC-BY-ND 4.0 International license.

Table 5: spa-types and Antimicrobial Resistance Among $S$. aureus positive isolates $(\mathrm{n}=12)$

617

\begin{tabular}{|c|c|c|c|c|c|c|c|c|c|c|c|c|c|c|c|c|c|c|c|c|c|c|c|c|}
\hline $\begin{array}{c}S . \\
\text { aureus } \\
\text { isolates }\end{array}$ & spa & $\mathrm{CC}$ & scn & $\begin{array}{l}\operatorname{mec} A / \\
\operatorname{mec} C\end{array}$ & $\begin{array}{l}\mathbf{P} \\
\mathbf{V} \\
\mathbf{L}\end{array}$ & $\begin{array}{l}\mathbf{S} \\
\mathbf{E}\end{array}$ & $\begin{array}{l}\mathbf{A} \\
\mathbf{M} \\
\mathbf{P}\end{array}$ & $\begin{array}{l}\mathbf{F} \\
\mathbf{O} \\
\mathbf{X}\end{array}$ & $\begin{array}{l}\text { C } \\
\mathbf{L} \\
\mathbf{I} \\
\mathbf{N}\end{array}$ & $\begin{array}{l}\mathbf{D} \\
\mathbf{A} \\
\mathbf{P}\end{array}$ & $\begin{array}{l}\mathbf{E} \\
\mathbf{R} \\
\mathbf{M}\end{array}$ & \begin{tabular}{l|}
$\mathbf{G}$ \\
$\mathbf{E}$ \\
$\mathbf{N}$
\end{tabular} & $\begin{array}{l}\mathbf{L} \\
\mathbf{Z} \\
\mathbf{D}\end{array}$ & $\begin{array}{l}\mathbf{M} \\
\mathbf{I} \\
\mathbf{N}\end{array}$ & $\begin{array}{l}\mathbf{M} \\
\mathbf{O} \\
\mathbf{X}\end{array}$ & $\begin{array}{l}\mathbf{N} \\
\mathbf{I} \\
\mathbf{T}\end{array}$ & $\begin{array}{l}\mathbf{O} \\
\mathbf{X} \\
\mathbf{A}\end{array}$ & \begin{tabular}{l|}
$\mathbf{P}$ \\
$\mathbf{E}$ \\
$\mathbf{N}$
\end{tabular} & $\begin{array}{l}\mathbf{Q} \\
\mathbf{P} \\
\mathbf{N} \\
- \\
\mathbf{D} \\
\mathbf{A} \\
\mathbf{L}\end{array}$ & $\begin{array}{l}\mathbf{R} \\
\mathbf{I} \\
\mathbf{F}\end{array}$ & $\begin{array}{l}\mathbf{S} \\
\mathbf{T} \\
\mathbf{P}\end{array}$ & \begin{tabular}{l|}
$\mathbf{T}$ \\
$\mathbf{E}$ \\
$\mathbf{T}$
\end{tabular} & $\begin{array}{c}\mathbf{T} \\
\mathbf{M} \\
\mathbf{P} \\
- \\
\mathbf{S} \\
\mathbf{U} \\
\mathbf{L}\end{array}$ & $\begin{array}{l}\mathbf{V} \\
\mathbf{A} \\
\mathbf{N}\end{array}$ \\
\hline I & $\mathrm{t} 701$ & 8 & & & & & & & & & & & & & & & & & & & & & & \\
\hline $\mathbf{J}$ & t3293 & 133 & & & & & & & & & & & & & & & & & & & & & & \\
\hline $\mathbf{K}$ & $\mathrm{t} 4562$ & $6^{+}$ & & & & & & & & & & & & & & & & & & & & & & \\
\hline O & $\mathrm{t} 062$ & $5 / 30$ & & & & & & & & & & & & & & & & & & & & & & \\
\hline Q & * & & & & & & & & & & & & & & & & & & & & & & & \\
\hline $\mathbf{T}$ & t062 & $5 / 30$ & & & & & & & & & & & & & & & & & & & & & & \\
\hline $\mathbf{U}$ & $\mathrm{t} 548$ & 2 & & & & & & & & & & & & & & & & & & & & & & \\
\hline V & t002 & 5 & & & & & & & & & & & & & & & & & & & & & & \\
\hline $\mathbf{X}$ & t548 & 2 & & & & & & & & & & & & & & & & & & & & & & \\
\hline DD & $\mathrm{t} 4562$ & & & & & & & & & & & & & & & & & & & & & & & \\
\hline $\mathbf{L L}$ & t548 & 2 & & & & & & & & & & & & & & & & & & & & & & \\
\hline MM & t002 & 5 & & & & & & & & & & & & & & & & & & & & & & \\
\hline
\end{tabular}

spa: spa-type; CC: clonal complex; scn: staphylococcal complement inhibitor protein gene; PVL: Panton-Valentine leucocidin; SE: staphylococcal enterotoxin genes A, B, C, and D (SEA, SEB, SEC, and SED); AMP: ampicillin; FOX: cefoxitin; CLIN: clindamycin; DAP: daptomycin; ERM: erythromycin; GEN: gentamycin; LZD: linezolid; MIN: minocycline; MOX: moxifloxicin; NIT: nitrofurantoin; OXA: oxacillin; PEN: penicillin; QPN-DAL: quinupristin-dalfropristin; RIF: rifampin; STP: streptomycin; TET: tetracycline; TMP-SUL: Trimethoprim-Sulfamethoxazole; VAN: vancomycin

* for Sample Q: suspect unknown spa-type; + for sample K: spa-type t4562 (11-10-21-17-34-25) is rare in the Ridom SpaServer but is related to the more common spa-type t304 (11-10-21-17-34-24-34-22-25), which has been associated with CC6. 